\title{
Polyhydroxyalkanoates are essential for maintenance of redox state in the Antarctic bacterium Pseudomonas sp. 14-3 during low temperature adaptation
}

\author{
Nicolás D. Ayub · Paula M. Tribelli • \\ Nancy I. López
}

Received: 3 July 2008/ Accepted: 19 September 2008/Published online: 18 October 2008

(C) Springer 2008

\begin{abstract}
Polyhydroxyalkanoates (PHAs) are highly reduced bacterial storage compounds that increase fitness in changing environments. We have previously shown that phaRBAC genes from the Antarctic bacterium Pseudomonas sp. 14-3 are located in a genomic island containing other genes probably related with its adaptability to cold environments. In this paper, Pseudomonas sp. 14-3 and its PHA synthase-minus mutant ( $p h a C$ ) were used to asses the effect of PHA accumulation on the adaptability to cold conditions. The phaC mutant was unable to grow at $10^{\circ} \mathrm{C}$ and was more susceptible to freezing than its parent strain. PHA was necessary for the development of the oxidative stress response induced by cold treatment. Addition of reduced compounds cystine and gluthathione suppressed the cold sensitive phenotype of the phaC mutant. Cold shock produced very rapid degradation of PHA in the wild type strain. The NADH/NAD ratio and NADPH content, estimated by diamide sensitivity, decreased strongly in the mutant after cold shock while only minor changes were observed in the wild type. Accordingly, the level of lipid peroxidation in the mutant strain was 25 -fold higher after temperature downshift. We propose that PHA metabolism modulates the availability of reducing equivalents, contributing to alleviate the oxidative stress produced by low temperature.
\end{abstract}

Communicated by L. Huang.

N. D. Ayub · P. M. Tribelli · N. I. López ( $₫)$

Departamento de Química Biológica,

Facultad de Ciencias Exactas y Naturales,

Universidad de Buenos Aires,

Intendente Güiraldes 2160,

C1428EGA Buenos Aires, Argentina

e-mail: nan@qb.fcen.uba.ar
Keywords Polyhydroxyalkanoates - Redox state Oxidative stress - Cold exposure - Pseudomonas . Antarctica

\section{Introduction}

Many environmental conditions impact microbial life. Among them, low temperature is a critical factor in controlling cell growth and survival. Exposure to low temperature results in decreased protein synthesis, reduced membrane fluidity, protein cold-denaturation, crystal ice formation, low diffusion rates across the membrane, and increased production of toxic reactive oxygen species (D'Amico et al. 2006). Microorganisms that inhabit cold environments are frequently exposed simultaneously to several stress conditions. For example, bacteria living in deep-sea environments have to tolerate low temperature as well as high pressure (Kato et al. 1998), while Antarctic microorganisms usually endure low temperature, nutrient deprivation, and high ultraviolet radiation (Margesin et al. 2007). In such extreme conditions, microorganisms that develop resistance to multiple stresses are selected (Hirsch et al. 2004).

Polyhydroxyalkanoates (PHAs) are highly reduced carbon storage compounds that are accumulated in most bacteria during unbalanced growth conditions (Madison and Huisman 1999). Accumulation and degradation of PHAs endow bacteria with enhanced survival, competition abilities, and stress tolerance, increasing fitness in changing environments (López et al. 1995; Ruiz et al. 2001; Kadouri et al. 2003; Ruiz et al. 2004; Pham et al. 2004; Kadouri et al. 2005).

We have analyzed an Antarctic bacterium, Pseudomonas sp. 14-3, that is able to accumulate polyhydroxybutyrate 
(PHB), the best known PHA. Pseudomonas sp. 14-3 synthesizes large amounts of PHB from octanoate, and shows high stress resistance compared with other related Pseudomonas species (Ayub et al. 2004). Genetic analysis demonstrates that Pseudomonas sp. 14-3 has a complete PHA biosynthesis cluster containing genes phaR, phaA, phaB, and phaC (Ayub et al. 2006). PHA biosynthesis in Pseudomonas sp. 14-3 proceeds from fatty acids but not from glucose or gluconate, due to a defective thiolase gene (phaA) (Ayub et al. 2006). It was recently found that PHA biosynthesis genes in this strain are located within a genomic island that also contains other genes probably related with its adaptability to Antarctic environments (Ayub et al. 2007). The fixation of horizontally transferred genes suggests that they confer a selective advantage on the recipient organism. However, the nature of this advantage usually remains unclear (Koonin et al. 2001).

In this paper, we investigated the role of PHA on the adaptation of Pseudomonas sp. 14-3 to cold conditions using a phaC mutant.

\section{Materials and methods}

\section{Bacterial strains}

Pseudomonas sp. 14-3, a PHB-producing strain with high stress resistance, was previously isolated in our laboratory from a temporary water pond in Antarctica (Ayub et al. 2004). Analysis of $16 \mathrm{~S}$ rDNA (EMBL accesion \# AJ583501) showed that this isolate was closely related with Pseudomonas veronii (Ayub et al. 2004). Pseudomonas putida KT2440 (Franklin et al. 1981) able to synthesize medium chain lengh PHA and P. putida GPp104 a PHA negative mutant (Huisman et al. 1991) were also used in this study.

Plasmids, mutant and recombinant strains construction

A 1,827 bp fragment from Pseudomonas sp. 14-3 phaC classI gene (EMBL accession \# AM262984) containing EcoRI and SacI internal restriction sites obtained by colony PCR amplification using primers $5^{\prime} \mathrm{CGCTCGAGCGCCTT}$ TCATCACCAGCTTCGCCCT3' and 5'CGCTCGAGCAT TGGCGCTGGCGAACCG3' (XhoI restriction sites underlined) was used to construct the mutant strain. The amplification fragment was digested with XhoI and subcloned into pBluescript SK (Stratagene). This plasmid was digested with $S a c$ I and religated in order to eliminate the pBluescript EcoRI site. Next, it was digested with EcoRI, and ligated with a kanamycin cassette obtained from plasmid pUC4 K (Pharmacia, San Francisco, California) cut with EcoRI. The resulting plasmid that does not replicate in Pseudomonas was introduced by transformation into competent cells of 14-3 prepared according to Lee et al. (2005). Transformants were selected by plating on LB agar containing $20 \mu \mathrm{g} / \mathrm{ml}$ of kanamycin $(\mathrm{Km}) . \mathrm{Km}^{\mathrm{R}}$ colonies were then screened for ampicillin (Amp) sensitivity in $0.5 \mathrm{NE} 2$ medium (Huisman et al. 1992) supplemented with $15 \mathrm{mM}$ sodium octanoate and Amp $(200 \mu \mathrm{g} / \mathrm{ml})$. A single $\mathrm{Km}^{\mathrm{R}}$-Amp ${ }^{\mathrm{S}}$ colony was chosen and named Pseudomonas sp. 14-3C. The double recombinant event in the strain 143C was checked by PCR analysis and its inability to synthesize PHB was confirmed by gas chromatography as previously described (Braunegg et al. 1978).

Plasmid pCTPHB, carrying the entire wild type phaC gene, was constructed by introducing an amplification fragment into pBBR1MCS (Kovach et al. 1995). The oligonucleotides used were 5'CGCTCGAGTGGCGACGCTG TGCATCGGC3' ${ }^{\prime}$ and $5^{\prime}$ CGCTCGAGCATTGGCGCTGGC GAAACCG3' containing XhoI sites (underlined). The pCTPHB plasmid was used to transform competent cells of P. putida GPp104 and Pseudomonas sp. 14-3C. Transformants were selected by plating on LB agar supplemented with chloramphenicol $(50 \mu \mathrm{g} / \mathrm{ml})$ and $\mathrm{Km}(20 \mu \mathrm{g} / \mathrm{ml})$ or only choramphenicol for 14-3C and GPp104 strains, respectively.

\section{Growth conditions}

Bacteria were grown in nutrient broth (NB) containing $15 \mathrm{mM}$ sodium octanoate (NBO) or $15 \mathrm{mM}$ glucose (NBG). In some experiments, NBO medium was supplemented with: cystine $(20 \mu \mathrm{M})$, glutathione $(50 \mu \mathrm{M})$, alanine $(100 \mu \mathrm{M})$, arginine $(100 \mu \mathrm{M})$, phenylalanine $(100 \mu \mathrm{M})$ or methionine $(100 \mu \mathrm{M})$. Cultures were performed in $125 \mathrm{ml}$ Erlenmeyer flasks containing $25 \mathrm{ml}$ of medium, incubated at 10 or $28^{\circ} \mathrm{C}$ with shaking $(200 \mathrm{rpm})$. Staining with Nile Blue (Ostle and Holt 1982) was used to examine the PHA accumulation phenotype. To test growth in a cold aerobic environment, overnight cultures grown at $28^{\circ} \mathrm{C}$ were used to inoculate media (pre-cooled to $10^{\circ} \mathrm{C}$ ) to an initial optical density $\left(\mathrm{OD}_{580 \mathrm{~nm}}\right)$ of 0.05 . Growth was monitored by measuring $\mathrm{OD}_{580 \mathrm{~nm}}$ for $72 \mathrm{~h}$. In order to examine bacterial tolerance at $10^{\circ} \mathrm{C}$, exponentially growing cells $\left(\mathrm{OD}_{580 \mathrm{~nm}}=0.5\right)$ at $28^{\circ} \mathrm{C}$ were downshifted to $10^{\circ} \mathrm{C}$, and incubated for 2 more days. The bacterial number was measured by colony counts on nutrient agar (NA) plates.

\section{Stress experiments}

Exponentially growing cells $\left(\mathrm{OD}_{580 \mathrm{~nm}}=0.5\right)$ in $\mathrm{NBO}$ medium at $28^{\circ} \mathrm{C}$ were exposed to thermal and oxidative stress. To assay cell survival to freezing, $0.1 \mathrm{ml}$ of the cultures were transferred to $0.9 \mathrm{ml}$ of $\mathrm{NBO}$ medium, precooled to $4^{\circ} \mathrm{C}$ and exposed to $-20^{\circ} \mathrm{C}$. The frozen 
suspension was thawed, mixed using vortex, and the number of viable cells after different times of exposure to $-20^{\circ} \mathrm{C}$ was measured by plating aliquots on NA. Survival was expressed as a percentage of the number of colony forming units at time zero, that was taken as $100 \%$. Sensitivity to $\mathrm{H}_{2} \mathrm{O}_{2}$ was measured by a disk inhibition assay as previously described (Ayub et al. 2004).

In order to test if cold exposure was able to induce the oxidative stress response, bacterial cells were grown in $\mathrm{NBO}$ medium at $28^{\circ} \mathrm{C}$ until $\mathrm{OD}_{580 \mathrm{~nm}}=0.5$ and then transferred to $10^{\circ} \mathrm{C}$. After 20 min of incubation at $10^{\circ} \mathrm{C}$, $2.5 \mathrm{ml}$ aliquots of the culture were inoculated into $125 \mathrm{ml}$ Erlenmeyer flasks containing $22.5 \mathrm{ml}$ of NBO medium supplemented with $0.05 \mathrm{mM} \mathrm{H}_{2} \mathrm{O}_{2}$, and growth was monitored by measuring $\mathrm{OD}_{580 \mathrm{~nm}}$ for $10 \mathrm{~h}$. Controls were treated in the same conditions without $\mathrm{H}_{2} \mathrm{O}_{2}$.

\section{Indicators of cellular redox state}

Pseudomonas sp. $14-3$ and $14-3 \mathrm{C}$ cells grown until $\mathrm{OD}_{580 \mathrm{~nm}}=0.5$ at $28^{\circ} \mathrm{C}$ in NBO were transferred to an ice bath for $20 \mathrm{~min}$. For the diamide sensitivity test, a $100-\mu \mathrm{l}$ aliquot of the bacterial suspension was spread on NA plates and three sterile filter paper disks impregnated with $10 \mu \mathrm{l}$ of $0.5 \mathrm{M}$ diamide in dimethyl sulfoxide were applied over the seeded plates. After overnight incubation at $28^{\circ} \mathrm{C}$, sensitivity was determined by measuring the diameter of the growth inhibition zone. Triplicate 1-ml culture samples were used for quantification of intracellular NADH/NAD ratio. Determination of these two pyridine nucleotides was performed as previously described (Leonardo et al. 1996). Absorption was measured at $570 \mathrm{~nm}$, and coenzyme standards from 0.05 to $1.5 \mathrm{mM}$ were used to calibrate the assay. Lipid damage was estimated through thiobarbituric acid-reactive substances (TBARS) concentration by the procedure of Semchyshyn et al. (2005). The amount of TBARS formed was expressed in picomoles of malondialdehyde (MDA) per milligram of protein, with an $\varepsilon_{535}$ of $156 \mathrm{mM}^{-1} \mathrm{~cm}^{-1}$.

\section{Results}

Characterization of the phaC mutant

The phaC mutant of Pseudomonas sp. 14-3, called 14-3C, showed similar duplication time $(67 \pm 2 \mathrm{~min}$ and $64 \pm 3$ min, respectively) in nutrient broth suplemented with sodium octanoate $(\mathrm{NBO})$ or glucose $(\mathrm{NBG})$ at $28^{\circ} \mathrm{C}$ compared with the parent strain. Quantification of the polymer production by gas chromatography showed that strain 14-3C was unable to synthesize PHB in several accumulation media, including NBO, where PHB content was less than $0.01 \mathrm{wt} \%$ (Table 1). Complementation of the mutant strain with pCTPHB carrying the $p h a C$, restored the PHB biosynthesis capability and also resulted in the production of an amount of PHB similar to that produced by the wild type strain (Table 1).

Growth and tolerance to low temperature

To investigate if PHA accumulation capability affects the growth at low temperatures, we performed aerobic cultures of Pseudomonas sp. $14-3$ at $10^{\circ} \mathrm{C}$ in NBO and NBG. This last medium does not allow PHA acumulation in this strain. Wild type cells cultured in $\mathrm{NBO}$ at $10^{\circ} \mathrm{C}$ arrived to stationary phase in 2 days, whereas cells cultured in NBG did not grow during a 3 day period (Fig. 1a). Accordingly, strain 14-3C, defective in the synthesis of PHB (Table 1), was unable to grow in $\mathrm{NBO}$ medium at $10^{\circ} \mathrm{C}$ (Fig. 1a). In addition, on nutrient agar plates supplemented with $15 \mathrm{mM}$ sodium octanoate in cold conditions $\left(10^{\circ} \mathrm{C}\right)$, macroscopic, well developed colonies of strain 14-3 were observed after 7 days of incubation, whilst strain 14-3C exhibited no significant growth (data not shown).

To further investigate the cold sensitive phenotype of the mutant strain, we assessed its tolerance to cold shock. Exponentially growing cultures in NBO at $28^{\circ} \mathrm{C}$ of strains $14-3$ and $14-3 \mathrm{C}$ were transferred to $10^{\circ} \mathrm{C}$. The wild type strain showed a slight increase in cell numbers following transfer to low temperature (Fig. 1b). By contrast, the number of culturable cells of the mutant showed a strong decrease with the temperature downshift (Fig. 1b).

We also analyzed resistance of cultures of 14-3 and 14$3 \mathrm{C}$ grown in $\mathrm{NBO}$ at $28^{\circ} \mathrm{C}$ to freezing $\left(-20^{\circ} \mathrm{C}\right)$, and observed that Pseudomonas sp. 14-3 was more resistant than its phaC mutant (Fig. 1c).

In all these experiments the behavior of the complemented strain, $14-3 \mathrm{C} / \mathrm{pCTPHB}$, was similar to the wild type strain (Fig. 1a, b, c).

Table 1 Production of PHB in Pseudomonas sp. 14-3 and recombinant strains at different incubation temperatures

\begin{tabular}{llc}
\hline Strain & \multicolumn{2}{l}{ PHB (wt \%) } \\
\cline { 2 - 3 } & $28^{\circ} \mathrm{C}$ & $10^{\circ} \mathrm{C}$ \\
\hline $14-3$ & $18 \pm 2$ & $24 \pm 2$ \\
$14-3 \mathrm{C}$ & $\mathrm{ND}$ & - \\
$14-3 \mathrm{C} / \mathrm{pCTPHB}$ & $20 \pm 3$ & $25 \pm 4$ \\
\hline
\end{tabular}

Determinations were performed during exponential growth phase in nutrient broth supplemented with $15 \mathrm{mM}$ octanoate [Wild type (14-3), PHA minus mutant (14-3C), and complemented strain (14-3C/ pCTPHB)]

$N D$ not detected 

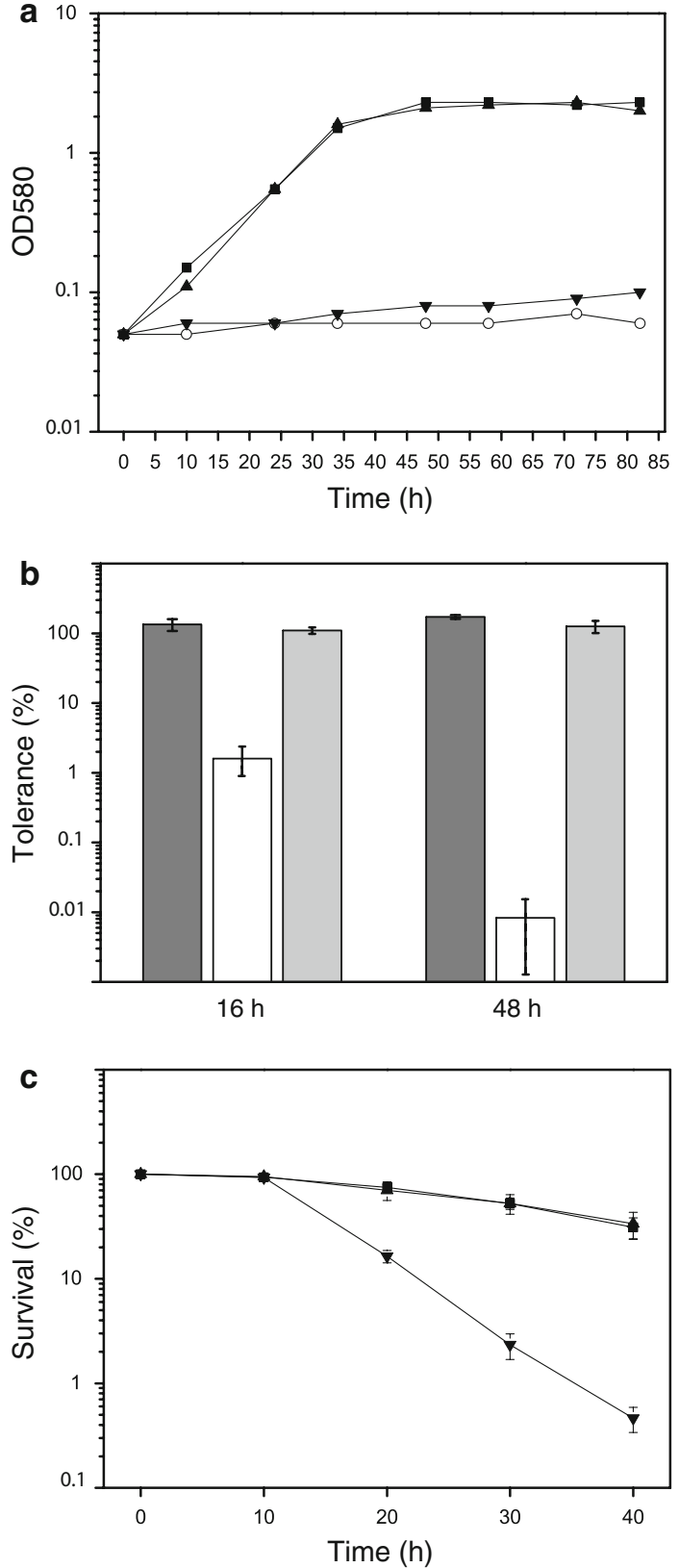

Fig. 1 Behavior of Pseudomonas sp. 14-3 and its PHA negative mutant under cold conditions. a Growth at $10^{\circ} \mathrm{C}$ of strains $14-3$ (rectangle), 14-3C (inverse triangle), and 14-3C/pCTPHB (triangle) in NBO (closed symbols) or 14-3 in NBG (open circle). Each experiment was performed twice and typical results are presented. Values represent media \pm SD of triplicate measurements. b Cold challenge. Exponentially growing cells of 14-3 (dark grey bar), 14-3C (white bar) and 14-3C/pCTPHB (light grey bar) strains in NBO medium were transferred from $28^{\circ} \mathrm{C}$ to $10^{\circ} \mathrm{C}$ during $16 \mathrm{~h}$ and $48 \mathrm{~h}$. c Survival to freezing $\left(-20^{\circ} \mathrm{C}\right)$ of $14-3$ (rectangle), 14-3C (inverse triangle), and 14-3C/pCTPHB (triangle). b, c Values represent media \pm SD of triplicate experiments. One hundred percent was considered to be the number of bacteria before the exposure to the stress agent
Role of PHA on the development of oxidative defenses during low temperature exposition

We examined the response of 14-3 and 14-3C to $\mathrm{H}_{2} \mathrm{O}_{2}$ after cold treatment. The cold $\left(20 \mathrm{~min}\right.$ at $\left.10^{\circ} \mathrm{C}\right)$ and non-coldtreated cultures did not exhibit any significant changes on growth (Fig. 2a), indicating that during a short time period the cold treatment did not have important effects on growth. Addition of a low concentration of $\mathrm{H}_{2} \mathrm{O}_{2}$ to noncold-treated cultures resulted in an increase of the lag growth phase in all strains analyzed (Fig. 2b). Pseudomonas sp. 14-3 showed a shorter initial lag than the mutant strain (Fig. 2b), in accordance with its higher tolerance to hydrogen peroxide (data not shown). Additionally, when cells were cold pre-treated before the addition of $\mathrm{H}_{2} \mathrm{O}_{2}$ the lag phase in the wild type strain was similar to the lag phase without $\mathrm{H}_{2} \mathrm{O}_{2}$ supplement, while no improvement in growth in the mutant strain was observed (Fig. 2b), indicating that PHA was necessary for the development of the antioxidant response induced by cold shock. The results observed for the complemented strain were comparable to those described for the wild type strain (Fig. 2b).

To investigate if the deficiency in antioxidative defenses was responsible for the cold sensitive phenotype of phaC mutant, we analyzed the growth of $14-3 \mathrm{C}$ at $10^{\circ} \mathrm{C}$ in NBO medium supplied with the reducing compounds glutathione ( $\gamma$-Glu-Cys-Gly) or cystine (Cys-Cys). Both compounds were able to suppress this phenotype, as the mutant was able to grow in the presence of the antioxidant compounds (Table 2). No growth was observed in NBO medium supplied with different amino acids that do not have antioxidant properties (Table 2).

To test whether the increased fitness in cold environments conferred by the ability to synthesize PHA could be extended to other Pseudomonas species, we performed low temperature and oxidative stress experiments using $P$. putida KT2440 and their PHA negative mutant $P$. putida GPp104. The duplication time at $28^{\circ} \mathrm{C}$ shown by GPp104 was similar to the wild type strain $(57 \pm 3 \mathrm{~min}$ and $62 \pm 2$ min, respectively). However, GPp104 was unable to grow and survive at $10^{\circ} \mathrm{C}$ in NBO (Fig. 3a, b). Similarly to 14-3C, GPp104 showed increased sensitivity to oxidative stress when compared to the wild type strain (Fig. 3c). The introduction of phaC from Pseudomonas sp. 14-3 conferred the capability to synthesize the polymer to the mutant strain GPp104 reaching values of $56 \pm 5$ wt $\%$ PHB in stationary phase cultures in NBO, and also restored the wild type phenotype (Fig. 3a-c).

Effect of cold shock on PHA content and redox state

On the basis of these experiments we hypothesized that the protective role of PHA under cold conditions could be 

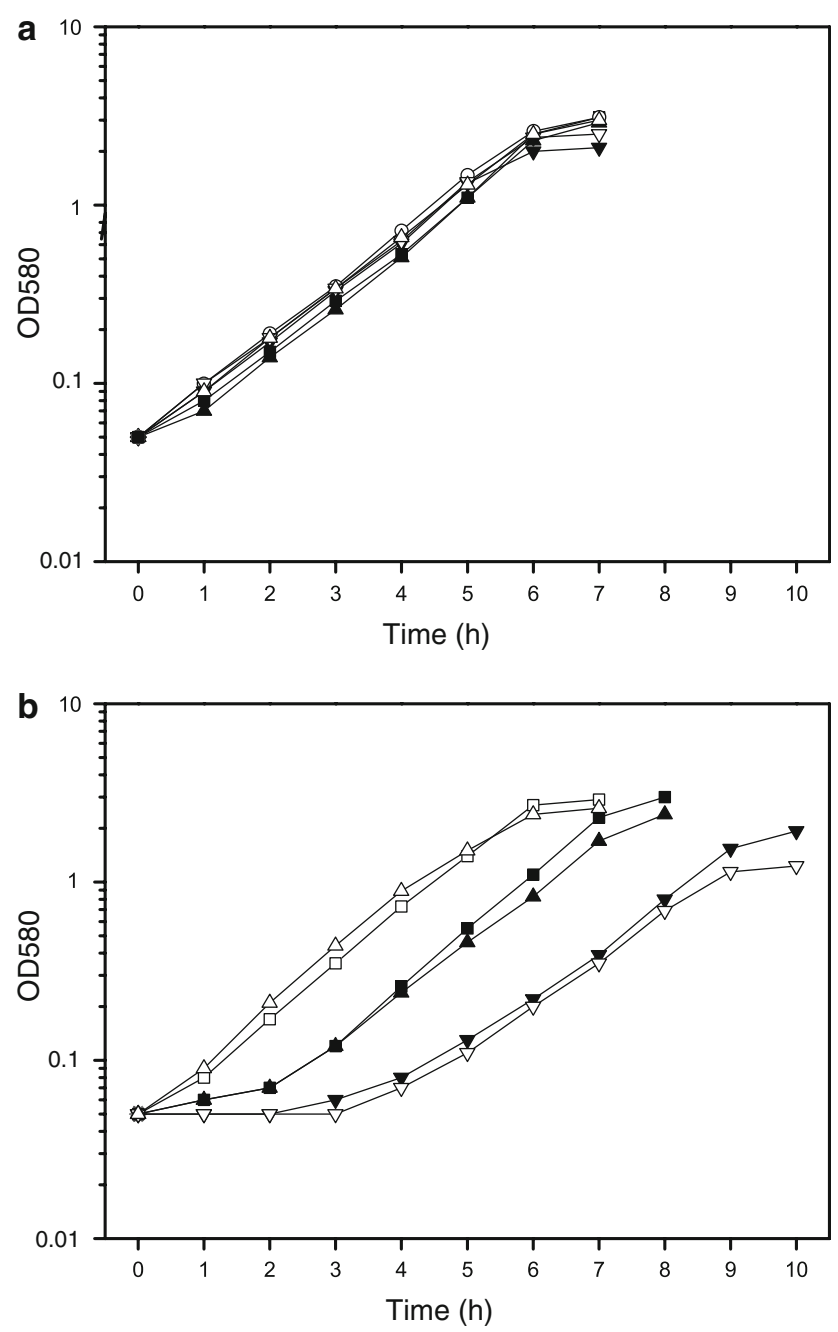

Fig. 2 Effect of phaC mutation on the growth in the presence of $\mathrm{H}_{2} \mathrm{O}_{2}$ after cold treatment. Cultures grown in NBO medium at $28^{\circ} \mathrm{C}$ until $\mathrm{OD}_{580}=0.5$ were shifted to $10^{\circ} \mathrm{C}$ for $20 \mathrm{~min}$. Then, $2.5 \mathrm{ml}$ aliquots of these cultures were inoculated into $22.5 \mathrm{ml}$ of the same medium supplemented with 0 (a) or $0.05 \mathrm{mM}(\mathbf{b}) \mathrm{H}_{2} \mathrm{O}_{2}$ and incubated at $28^{\circ} \mathrm{C}$ until early stationary phase. Strains: $14-3$ (rectangle), $14-3 \mathrm{C}$ (inverse triangle), and 14-3C/pCTPHB (triangle). Open and closed symbols designate cultures cold-pretreated and non-cold- pretreated, respectively. Each experiment was performed twice and typical results are presented. Values represent media \pm SD of triplicate measurements

related with its function as a modulator of the pool of reducing equivalents. To test this hypothesis, we assessed the ratio NADH/NAD as an indicator of intracellular redox state and the sensitivity to diamide as a rough estimation of NADPH availability (Butler et al. 2002) in line with PHA degradation after cold shock. In addition, the accumulation of damage products of oxidative stress resulting from cold exposure was analyzed by measuring thiobarbituric acidreactive substances (TBARS) that indicate the amount of oxidized lipids. In all the experiments, exponentially growing cultures of Pseudomonas sp 14-3 and its phaC
Table 2 Effect of antioxidant compounds on growth at $10^{\circ} \mathrm{C}$ of the phaC mutant

\begin{tabular}{ll}
\hline Strain/medium & $\begin{array}{l}\text { Growth rate } \\
\left(\mathrm{h}^{-1}\right)\end{array}$ \\
\hline 14-3 NBO & 0.0389 \\
$14-3 \mathrm{C}$ NBO & No growth \\
14-3C NBO cystine $(20 \mu \mathrm{M})$ & 0.0253 \\
14-3C NBO glutathione $(50 \mu \mathrm{M})$ & 0.0242 \\
14-3C NBO alanine $(100 \mu \mathrm{M})$ & No growth \\
14-3C NBO arginine $(100 \mu \mathrm{M})$ & No growth \\
14-3C NBO phenylalanine $(100 \mu \mathrm{M})$ & No growth \\
14-3C NBO methionine $(100 \mu \mathrm{M})$ & No growth \\
\hline
\end{tabular}

Growth rate was derived from turbidimetric measurements at $580 \mathrm{~nm}$ on log-phase cultures. Data are expressed as the mean from three independent experiments

mutant were cold challenged in an ice bath during $20 \mathrm{~min}$, and cellular redox state indicators were measured before and after cold shock. The amount of PHB in strain 14-3 decreased drastically reaching values of $0.39 \pm 0.04 \mathrm{wt} \%$. The NADH/NAD ratio in the wild type strain showed a slight decrease (Fig. 4a). On the contrary, the NADH/NAD ratio in mutant cells dropped to values roughly threefold lower than those observed in non-cold shocked cells (Fig. 4a). Complementation with phaC gene allowed the reversion of the redox imbalance (Fig. 4a).

Despite the fact that the wild type and the mutant strain showed similar inhibition zones when exposed to diamide $(12.0 \pm 1.0$ and $14.7 \pm 0.6 \mathrm{~mm}$, respectively) before ice treatment, the PHA minus strain showed higher diamide sensitivity $(18.0 \pm 1.0 \mathrm{~mm})$ in comparison with the wild type $(13.3 \pm 0.6 \mathrm{~mm})$ after cold shock (Student's $t$ test, $\mathrm{P}<0.002)$. This indicated that the phaC mutant presented alterations in both the NADH/NAD ratio and the intracellular NADPH content under cold conditions. The amount of TBARS after cold challenge increased drastically (25-fold) in the mutant strain (from $428 \pm 86$ to $10,574 \pm 2,229 \mathrm{pmol} \mathrm{MDA} / \mathrm{mg}$ protein), while the increase observed for the wild type strain was significantly lower (from $107 \pm 17$ to $429 \pm 87 \mathrm{pmol} \mathrm{MDA} / \mathrm{mg}$ protein) (Fig. 4b). Complementation with the phaC decreased the level of oxidative damage in lipids (Fig. 4b).

\section{Discussion}

The phaC gene of Pseudomonas sp. 14-3 is located in a large genomic island-like element (Ayub et al. 2007). Horizontally transferred genes are believed to persist if they provide a selective benefit to the host (Lawrence 1999). In this study we have shown that the capability to synthesize PHA encoded by phaC was essential for the 

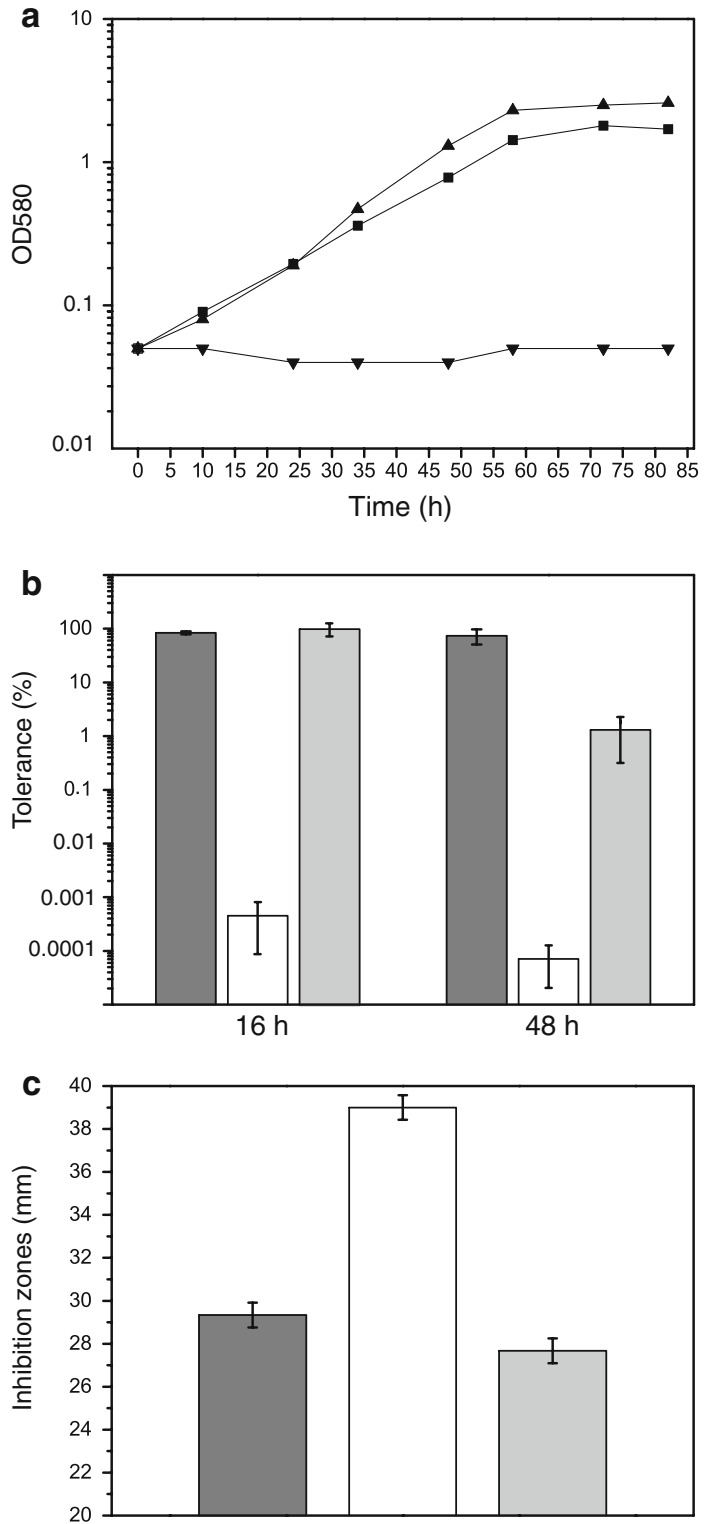

Fig. 3 Performance of Pseudomonas putida KT2440 and its PHA negative mutant under cold and oxidative stress. a Growth at $10^{\circ} \mathrm{C}$ of strains KT2440 (rectangle), GPp104 (inverse triangle), and GPp104/ pCTPHB (triangle) in NBO. b Cold challenge. Exponentially growing cells of KT2440 (dark grey bar), GPp104 (white bar) and GPp104/pCTPHB (light grey bar) strains in NBO medium were transferred from $28^{\circ} \mathrm{C}$ to $10^{\circ} \mathrm{C}$ during $16 \mathrm{~h}$ and $48 \mathrm{~h}$. One hundred percent was considered to be the number of bacteria before the temperature downshift. c Sensitivity to $30 \%$ of $\mathrm{H}_{2} \mathrm{O}_{2}$ of KT2440 (dark grey bar), GPp104 (white bar) and GPp104/pCTPHB (light grey bar). $\mathbf{a}, \mathbf{b}$ and $\mathbf{c}$ Each experiment was performed twice and typical results are presented. Values represent media \pm SD of triplicate measurements

adaptability to cold conditions in the Antarctic bacterium Pseudomonas sp. 14-3. Bacterial survival and stress resistance studies are important for many aspects of bioremediation, biocontrol, and plant growth promotion. Pseudomonas species are highly versatile microorganisms,
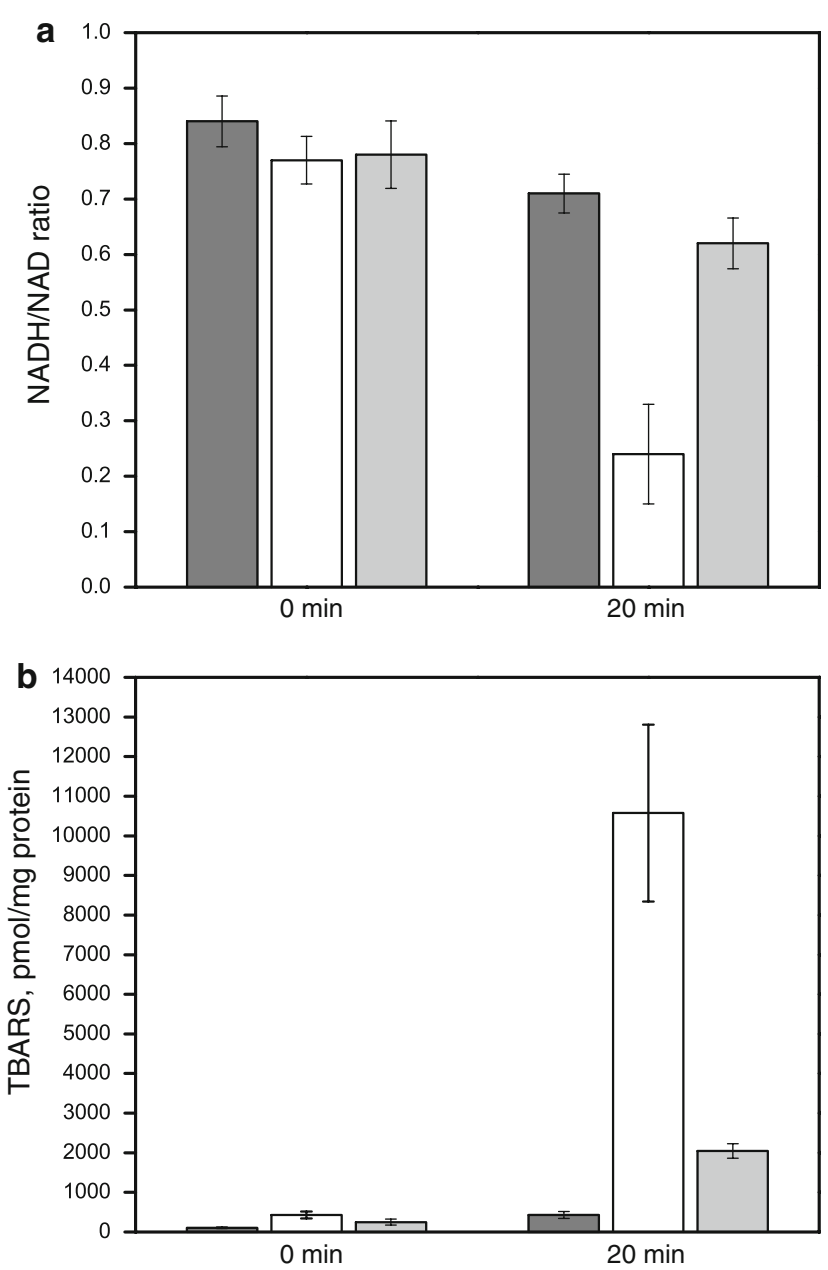

Fig. 4 Effect of phaC mutation on intracellular redox state and oxidative lipid damage after cold shock. NADH/NAD ratio (a) and TBARS (b) in 14-3 (dark grey bar), 14-3C (white bar) and 14-3C/ pCTPHB (light grey bar) strains before and after cold shock (ice treatment for $20 \mathrm{~min}$ ). Values represent media $\pm \mathrm{SD}$ of triplicate measurements

among them $P$. putida KT2440 is one of the best characterized Pseudomonas used in biotechnology and agriculture applications. We found that PHA biosynthesis was also necessary for growth at $10^{\circ} \mathrm{C}$ and resistance to cold shock in this strain. Recently, a study based on the screening for cold sensitive Tn5 mutants in $P$. putida KT2440 allowed the identification of 13 essential genes for life at low temperatures (Reva et al., 2006). PHA genes were not included inside this group of genes, probably due to the duplication of synthase genes (Nelson et al. 2002). Our results suggest that the increased fitness in cold environments conferred by the ability to synthesize PHA to Pseudomonas sp. 14-3 could be extended to other Pseudomonas species that were not isolated from Antarctic environments.

In order to elucidate some of the mechanisms involved in the increased fitness conferred by PHA we analyzed 
several indicators of intracellular redox state. It has been reported that organisms living at low temperature either bacteria, yeasts, plants or animals, are exposed to oxidative stress generated by cold conditions (e.g. Kane et al. 1996; Salahudeen et al. 2000; Liu et al. 2002; Gocheva et al. 2006). Therefore, low temperatures induce the production of antioxidant enzymes (e.g. catalase, superoxide dismutase, and glutathione peroxidase) that utilize reduced nicotinamide dinucleotides as cofactors (Smirnova et al. 2001; Zhang et al. 2003). The phaC mutant of Pseudomonas sp. 14-3 was unable to develop the oxidative resistance after cold exposure indicating a crucial function of PHA in cold-inducible antioxidant defense. Low temperature growth experiments using the reducing compounds cystine and glutathione further suggest that the cold sensitive phenotype of the phaC mutant was due to an insufficient availability of reducing equivalents. PHAs are highly reduced storage materials which are involved in a dynamic process of biosynthesis and degradation (Yan et al. 2000). Because of this, polymer degradation could supply the reductive power necessary to subdue the oxidative stress under cold conditions. This hypothesis is supported by several experiments performed in this work. The wild type strain showed a very rapid PHA degradation after cold shock, associated with the maintenance of $\mathrm{NADH} / \mathrm{NAD}$ ratio, total NADPH content, and low lipid damage. In addition, the occurrence of redox imbalance and lipid peroxidation in the mutant after cold shock could be related with its impaired growth at $10^{\circ} \mathrm{C}$. To our knowledge, this is the first report suggesting a relationship between the intracellular redox state mediated by PHA and the adaptability to cold environments.

Acknowledgments We thank Dr. Beatriz Méndez and Dr. M. Julia Pettinari for their helpful comments and critical reading of the manuscript. We also are grateful to Dr. María del Carmen Ríos for her advice with the measurements of lipid peroxidation, and two anonymous reviewers who provided useful criticisms. This work was supported by grants from UBA and CONICET. N.I.L. is a career investigator from CONICET. N.D.A and P.M.T. have a graduate student fellowship from CONICET.

\section{References}

Ayub ND, Pettinari MJ, Ruiz JA, López NI (2004) A polyhydroxybutyrate-producing Pseudomonas sp. isolated from Antarctic environments with high stress resistance. Curr Microbiol 49:170-174

Ayub ND, Pettinari MJ, Méndez BS, López NI (2006) Impaired polyhydroxybutyrate biosynthesis from glucose in Pseudomonas sp. $14-3$ is due to a defective $\beta$-ketothiolase gene. FEMS Microbiol Lett 264:125-131

Ayub ND, Pettinari MJ, Méndez BS, López NI (2007) The polyhydroxyalkanoate genes of a stress resistant Antarctic Pseudomonas are situated within a genomic island. Plasmid 58:240-248
Braunegg G, Sonnleitner B, Lafferty RM (1978) A rapid gas chromatographic method for the determination of poly-ßhydroxybutyric acid in microbial biomass. Eur J Appl Microbial Biotechnol 6:29-37

Butler MJ, Bruheim P, Jovetic S, Marinelli F, Postma PW, Bibb MJ (2002) Engineering of primary carbon metabolism for improved antibiotic production in Streptomyces lividans. Appl Environ Microbiol 68:4731-4739

D'Amico S, Collins T, Marx JC, Feller G, Gerday C (2006) Psychrophilic microorganisms: challenges for life. EMBO Rep 7:385-389

Franklin FCH, Bagdasarian M, Bagdasarian MM, Timmis KN (1981) Molecular and functional analysis of the TOL plasmid pWW0 from Pseudomonas putida and cloning of genes for the entire regulated aromatic ring meta-cleavage pathway. Proc Natl Acad Sci USA 78:7458-7462

Gocheva YG, Krumova ET, Slokoska LS, Miteva JG, Vassilev SV, Angelova MB (2006) Cell response of Antarctic and temperate strains of Penicillium spp. to different growth temperature. Mycol Res 110:1347-1354

Hirsch P, Gallikowski CA, Siebert J, Peissl K, Kroppenstedt R, Schumann P, Stackebrandt E, Anderson R (2004) Deinococcus frigens sp. nov., Deinococcus saxicola sp.nov., and Deinococcus marmoris sp.nov., low temperature and draught tolerating, UV-resistant bacteria from continental Antarctica. Syst Appl Microbiol 27:636-645

Huisman GW, Wonink E, Meima R, Kazemier B, Terpstra P, Witholt B (1991) Metabolism of poly(3-hydroxyalkanoates) (PHAs) by Pseudomonas oleovorans. Identification and sequences of genes and function of the encoded proteins in the synthesis and degradation of PHA. J Biol Chem 266:2191-2198

Huisman GW, Wonink E, de Koning G, Preusting H, Witholt B (1992) Synthesis of poly(3-hydroxyalkanoates) by mutant and recombinant Pseudomonas strains. Appl Microbiol Biotechnol $38: 1-5$

Kadouri D, Jurkevitch D, Okon Y (2003) Poly $\beta$-hydroxybutyrate depolymerase (PhaZ) in Azospirillum brasilense and characterization of a phaZ mutant. Arch Microbiol 180:309-318

Kadouri D, Jurkevitch E, Okon Y, Castro-Sowinski S (2005) Ecological and agricultural significance of bacterial polyhydroxyalkanoates. Crit Rev Microbiol 31:55-67

Kane DO, Gill V, Boyd P, Burdon R (1996) Chilling, oxidative stress and antioxidant responses in Arabidopsis thaliana callus. Planta 198:371-377

Kato C, Li L, Nogi Y, Nakamura Y, Tamaoka J, Horikoshi K (1998) Extremelly barophilic bacteria isolated from the Mariana Trench, Challenger Deep, at a depth of 11,000 meters. Appl Environ Microbiol 64:1510-1513

Koonin EV, Makarova KS, Aravind L (2001) Horizontal gene transfer in Prokaryotes: quantification and classification. Annu Rev Microbiol 55:709-742

Kovach ME, Elzer PH, Hill DS, Robertson GT, Farris MA, Roop RM, Peterson KM (1995) Four new derivatives of the broad hostrange cloning vector $\mathrm{pBBR} 1 \mathrm{MCS}$, carrying different antibioticresistance cassettes. Gene 166:175-176

Lawrence JG (1999) Gene transfer, speciation, and the evolution of bacterial genomes. Curr Opin Microbiol 2:519-523

Lee SH, Lee SY, Park BC (2005) Cell surface display of lipase in Pseudomonas putida KT2442 using OprF as an anchoring motif and its biocatalytic applications. Appl Environ Microbiol 71:8581-8586

Leonardo MR, Dailly Y, Clark DP (1996) Role of NAD in regulating the adhE gene of Escherichia coli. J Bacteriol 178:6013-6018

Liu S, Graham JE, Bigelow L, Morse PD, Wilkinson BJ (2002) Identification of Listeria monocytogenes genes expressed in 
response to growth at low temperature. Appl Environ Microbiol 68:1697-1705

López NI, Floccari ME, Garcia AF, Steinbüchel A, Mendez BS (1995) Effect of poly-3-hydroxybutyrate content on the starvation survival of bacteria in natural waters. FEMS Microbiol Ecol 16:95-101

Madison LL, Huisman GW (1999) Metabolic engineering of poly (3-hydroxyalkanoates): from DNA to plastic. Microbiol Mol Biol Rev 63:21-53

Margesin R, Neuner G, Storey KB (2007) Cold-loving microbes, plants, and animals-fundamental and applied aspects. Naturwissenschaften 94:77-99

Nelson KE, Weinel C, Paulsen IT, Dodson RJ, Hilbert H, Martins dos Santos VA, Fouts DE, Gill SR, Pop M, Holmes M, Brinkac L, Beanan M, DeBoy RT, Daugherty S, Kolonay J, Madupu R, Nelson W, White O, Peterson J, Khouri H, Hance I, Chris Lee P, Holtzapple E, Scanlan D, Tran K, Moazzez A, Utterback T, Rizzo M, Lee K, Kosack D, Moestl D, Wedler H, Lauber J, Stjepandic D, Hoheisel J, Straetz M, Heim S, Kiewitz C, Eisen JA, Timmis KN, Düsterhöft A, Tümmler B, Fraser CM (2002) Complete genome sequence and comparative analysis of the metabolically versatile Pseudomonas putida KT2440. Environ Microbiol 4:799-808

Ostle A, Holt JG (1982) Nile Blue A as a fluorescent stain for polyhydroxybutyrate. Appl Environ Microbiol 44:238-241

Pham TH, Webb JS, Rehm BHA (2004) The role of polyhydroxyalkanoate biosynthesis by Pseudomonas aeruginosa in rhamnolipid and alginate production as well as stress tolerance and biofilm formation. Microbiology 150:3405-3413
Reva ON, Weinel C, Weinel M, Böhm K, Stjepandic D, Hoheisel JD, Tümmler B (2006) Functional genomics of stress response in Pseudomonas putida KT2440. J Bacteriol 188:4079-4092

Ruiz JA, López NI, Fernández RO, Méndez BS (2001) Polyhydroxyalkanoate degradation is associated with nucleotide accumulation and enhances stress resistance and survival of Pseudomonas oleovorans in natural waters microcosms. Appl Environ Microbiol 67:225-230

Ruiz JA, López NI, Méndez BS (2004) rpoS gene expression in carbon starved cultures of the polyhydroxyalkanoate accumulating species Pseudomonas oleovorans. Curr Microbiol 48:396-400

Salahudeen AK, Huang H, Patel P, Jenkins JK (2000) Mechanism and prevention of cold storage-induced human renal tubular cell injury. Transplantation 70:1424-1431

Semchyshyn H, Bagnyukova T, Storey K, Lushchak V (2005) Hydrogen peroxide increases the activities of soxRS regulon enzymes and the levels of oxidized proteins and lipids in Escherichia coli. Cell Biol Int 29:898-902

Smirnova GV, Zakirova ON, Oktyabrskii ON (2001) The role of antioxidant systems in the cold stress response of Escherichia coli. Microbiology 70:45-50

Yan YB, Wu Q, Zhang RQ (2000) Dynamic accumulation and degradation of poly(3-hydroxyalkanoates) in living cells of Azotobacter vinelandii UWD characterized by ${ }^{13} \mathrm{C}$ NMR. FEMS Microbiol Lett 193:269-273

Zhang L, Onda K, Imai R, Fukuda R, Horiuchi H, Ohtaa A (2003) Growth temperature downshift induces antioxidant response in Saccharomyces cerevisiae. Biochem Biophys Res Commun 307:308-314 